\title{
Oviposição do curuquerê e alimentação de suas lagartas neonatas em algodoeiros tratados com caulim
}

\author{
Suziane Gomes Gonçalves ${ }^{(1)}$, Carlos Alberto Domingues da Silva(2), Marília de Macêdo Freire Duarte ${ }^{(1)}$ \\ e Eduardo Domingos Vasconcelos ${ }^{(2)}$
}

(1)Universidade Estadual da Paraíba, Rua das Baraúnas, o 351, Bairro Universitário, Bodocongó, CEP 58429-500 Campina Grande, PB, Brasil. E-mail: suzianebio@hotmail.com, duartmarilia@hotmail.com ${ }^{(2)}$ Embrapa Algodão, Rua Oswaldo Cruz, no 1.143, Centenário, Caixa Postal 174, CEP 58428-095 Campina Grande, PB, Brasil. E-mail: carlos.domingues-silva@embrapa.br, eduardo.vasconcelos@embrapa.br

Resumo - O objetivo deste trabalho foi avaliar a capacidade do caulim de afetar a oviposição e a alimentação de Alabama argillacea (Lepidoptera: Noctuidae) em algodoeiro. Determinou-se a preferência de oviposição, a viabilidade de ovos e o consumo das lagartas de primeiro instar de $A$. argillacea, em folhas de algodão tratadas ou não com caulim. A preferência de oviposição foi determinada por teste de escolha e confinamento, em delineamento experimental de blocos ao acaso, em arranjo fatorial $2 \times 7$, representado pelos tratamentos com caulim em água destilada $\left(60 \mathrm{~g} \mathrm{~L}^{-1}\right)$ ou somente água destilada (testemunha), e pela avaliação de sete estruturas vegetais da planta. $\mathrm{O}$ consumo pelas lagartas de primeiro instar foi determinado em delineamento experimental inteiramente casualizado, em arranjo fatorial $2 \times 4$, representado pelo tratamento com caulim em água destilada, pela testemunha e pelos quatro períodos de observação (6, 12, 24 e 48 horas). A oviposição das mariposas do curuquerê-do-algodoeiro foi reduzida nas plantas de algodão tratadas com caulim; no entanto, a viabilidade dos ovos não foi afetada. A folha da haste foi a estrutura preferida para oviposição. A sobrevivência e o consumo de lagartas de primeiro instar do curuquerê são menores nas plantas de algodão tratadas com caulim.

Termos para indexação: Alabama argillacea, Gossypium hirsutum, filme de partículas, herbivoria.

\section{Oviposition of leafworm and feeding of its neonate larvae on cotton treated with kaolin}

\begin{abstract}
The objective of this work was to evaluate the ability of kaolin to affect oviposition and feeding of Alabama argillacea (Lepidoptera: Noctuidae) on cotton. The oviposition preference, the egg viability, and the feed consumption of the first instar larvae of A. argillacea were determined on cotton leaves treated or not with kaolin. The oviposition preference was determined under choice test and confinement, in a randomized complete block design, in a $2 \times 7$ factorial arrangement, represented by the treatments with kaolin in distilled water $\left(60 \mathrm{~g} \mathrm{~L}^{-1}\right)$ or distilled water only (control), and by the evaluation of seven plant structures. The feed consumption by the first instar larvae was determined in a completely randomized design, in a $2 \times 4$ factorial arrangement, represented by the treatment with kaolin in distilled water, by the control, and by the four observation periods $(6,12,24$, and 48 hours). The oviposition of cotton leafworm moths was reduced in cotton plants treated with kaolin; however, the viability of eggs was not affected. Leaf stem was the preferred structure for oviposition. Survival and feed consumption of first instar larvae of cotton leafworm are lower on cotton plants treated with kaolin.
\end{abstract}

Index terms: Alabama argillacea, Gossypium hirsutum, herbivory, particle film.

\section{Introdução}

O curuquerê-do-algodoeiro, Alabama argillacea (Hübner, 1818) (Lepidoptera: Noctuidae), é considerado praga importante no Brasil, pois é responsável por desfolhamentos severos e perdas entre 21 e $35 \%$ da produção dessa malvácea (Ramalho et al., 2014).

As lagartas do curuquerê atacam preferencialmente as folhas novas do ponteiro (Fernandes et al., 2007).
Ataques mais intensos são caracterizados pelo consumo das folhas medianas e baixas, ramos, talos e maçãs, o que resulta na destruição total ou parcial da planta (Quirino \& Soares, 2001). A ocorrência de ataque no período da abertura das maçãs provoca o amadurecimento precoce dos frutos, diminuição da resistência das fibras (Pavinato et al., 2011) e redução da produção de fotoassimilados ligados à formação do capulho (Silva et al., 2011). 
A principal tática de controle desse inseto é a química, por meio de pulverizações com inseticidas sintéticos (Costa et al., 2010). Esses inseticidas são eficazes, relativamente econômicos, adaptáveis à maioria das situações, de uso flexível e, portanto, considerados uma ferramenta de grande valor no manejo de pragas (Alves \& Serikawa, 2006).

No entanto, a utilização de inseticidas contra os insetos-praga do algodão, pelos produtores brasileiros tem, em geral, provocado desequilíbrios biológicos no agroecossistema do algodoeiro, com o surgimento de populações de insetos resistentes (Silva et al., 2011), e elevadas taxas de mortalidade de insetos entomófagos, predadores e parasitoides que se constituem nos principais grupos de inimigos naturais, que atuam na regulação populacional dos insetos-praga em muitos sistemas agrícolas (Evangelista Júnior et al., 2006).

Para reduzir o efeito negativo desses inseticidas, é necessário desenvolver medidas alternativas de controle para manejar as pragas agrícolas. A tecnologia de filme de partículas de caulim é considerada uma alternativa viável, capaz de reduzir e otimizar o uso de inseticidas destinados ao controle de pragas importantes do algodoeiro (Silva \& Ramalho, 2013). Vários estudos têm mostrado que as formulações hidrofóbicas do filme de partículas à base de caulim podem proteger com eficiência plantas hospedeiras de coleópteros, lepidópteros, sugadores e ácaros (Showler, 2003; Sisterson et al., 2003; Sackett et al., 2005; Alavo et al., 2010; Alavo et al., 2011; Silva \& Ramalho, 2013; Neves et al., 2014). Aplicações de caulim podem repelir pragas, interromper a alimentação e impedir a oviposição de Helicoverpa armigera (Lepidoptera: Noctuidae) (Alavo, 2006). Entretanto, informações sobre o efeito do caulim contra o curuquerê-do-algodoeiro não foram encontradas.

Mariposas são capazes de reconhecer e depositar ovos em hospedeiros mais favoráveis ao desenvolvimento de seus descendentes (Papaj \& Rausher, 1983; Gripenberg et al., 2010). O curuquerê é uma espécie monofágica, condicionada para localizar e selecionar o alimento por meio de pistas visuais, químicas e gustativas (Papaj \& Rausher, 1983). Por isto, é provável que as plantas pulverizadas por caulim sejam capazes de prejudicar o comportamento de postura e alimentação dessa praga.

O objetivo deste trabalho foi avaliar a capacidade do caulim de afetar a oviposição e alimentação de Alabama argillacea em algodoeiro.

\section{Material e Métodos}

O trabalho foi desenvolvido no Laboratório de Entomologia e no Campo Experimental da Embrapa Algodão (7º $13^{\prime} 50^{\prime \prime} \mathrm{S}$ e $\left.35^{\circ} 52^{\prime} 52^{\prime \prime} \mathrm{W}\right)$, em Campina Grande, PB, Brasil.

Os espécimes de $A$. argillacea utilizados nos bioensaios provieram das colônias de criação massal da Unidade de Patologia e Biologia Molecular de Insetos, da Embrapa Algodão, criadas em dieta natural, de acordo com Medeiros et al. (1998).

A preferência de $A$. argillacea por realizar a oviposição em diferentes estruturas das plantas de algodão com e sem caulim foi avaliada por meio de teste de escolha e confinamento, em plantas de algodão 'BRS 286', que foram semeadas em vasos de plástico com capacidade para quatro litros. Os vasos foram preenchidos com solo coletado do campo experimental, classificado como Neossolo Regolítico eutrófico (Silva, 2009), misturado a esterco bovino à proporção de 3:1 conforme recomendado pelo Laboratório de Solos da Embrapa Algodão. Após a semeadura, as plantas contidas nos vasos foram mantidas em casa de vegetação até os 30 dias de idade (presença dos primeiros botões florais). O controle de insetos sugadores presentes nas plantas de algodão, antes do início do experimento, foi realizado com extrato aquoso de Nicotiana tabacum L. (Solanaceae).

Para o teste de escolha, instalaram-se quatro telados com armação de madeira, com $2 \mathrm{~m}$ de largura, por $2 \mathrm{~m}$ de comprimento e 1,6 $\mathrm{m}$ de altura, em área de $200 \mathrm{~m}^{2}$. Utilizou-se o delineamento experimental de blocos ao acaso em arranjo fatorial $2 \times 7$, representado pelo tratamento da planta de algodão, com suspensão de caulim em água destilada a $60 \mathrm{~g} \mathrm{~L}^{-1}$, além da testemunha (água destilada) e pelas seguintes estruturas vegetais da planta: $E_{1}$, broto; $E_{2}$, botão floral; $E_{3}$, haste; $E_{4}$, folha da haste (1 $\stackrel{a}{a}, 2^{a}, 3^{a}, 4^{a}, 5^{a}, 6^{a}, 7 \underline{a}, 8^{a}, 9^{a}$ e $10^{a}$ folhas da haste principal, contadas a partir do ápice para a base); $\mathrm{E}_{5}$, folhas do $1^{\mathrm{o}}$ e $2^{\mathrm{o}}$ ramos frutíferos; $\mathrm{E}_{6}$, folhas do 3 e 4응 ramos frutíferos; e $\mathrm{E}_{7}$, folhas do 5o e 6o ramos frutíferos. A dose de caulim foi escolhida com base em estudos anteriores, realizados com lepidópteros-praga do algodoeiro - o de Showler (2003), em folha de algodão, contra Spodoptera exigua, e o de Sackett et al. (2003), em folha de maçã, contra Choristoneura rosaceana (Harris) (Lepidoptera: Tortricidae). A solução de caulim foi aplicada às plantas com uso de um pulverizador manual, até que elas ficassem 
totalmente recobertas pelo produto. Cada bloco constituiu-se de um telado, que continha oito vasos, com quatro plantas pulverizadas com caulim e quatro sem caulim. Os vasos foram distribuídos ao acaso, de forma equidistante e em círculo, nas bordas de cada telado. No centro de cada telado, foram liberados dez casais de mariposas de A. argillacea, para efetuar postura. Os casais foram unidos três dias antes da liberação, para realizar a cópula. As liberações foram feitas no início da escotófase. Setenta e duas horas após a liberação, as plantas foram coletadas e levadas ao laboratório para quantificação do número de ovos por estrutura vegetativa da planta. As estruturas vegetativas foram examinadas com um estereomicroscópio com aumento de 25 vezes. Determinou-se a distribuição vertical e a viabilidade dos ovos, nas estruturas vegetais do algodoeiro, por tratamento.

Para o teste de confinamento (sem chance de escolha), utilizaram-se telados com $0,40 \mathrm{~m}$ de largura, por $0,40 \mathrm{~m}$ de comprimento e $0,80 \mathrm{~m}$ de altura. $\mathrm{O}$ delineamento experimental, os tratamentos, a distribuição vertical e a contagem dos ovos nas estruturas vegetais seguiram o método utilizado no teste de escolha, mas os vasos com as plantas foram individualizados por telado e distribuídos ao acaso. Em cada telado, foi liberado um casal de $A$. argillacea, para efetuar a postura. Os casais foram unidos três dias antes da liberação, para realizar a cópula.

Para avaliar o consumo foliar por lagartas de primeiro instar, em folhas de algodão com ou sem caulim, aos trinta dias de idade (presença dos primeiros botões florais), as folhas com aproximadamente $14 \mathrm{~cm}^{2} \mathrm{de}$ área foliar, bem como seus pecíolos, foram removidas do terço superior da planta, lavadas em solução de hipoclorito de sódio a $5 \%$ e secas com papel-toalha até o início do bioensaio.

Utilizou-se o delineamento experimental inteiramente casualizado, em arranjo fatorial $2 \times 4$, representado pelo revestimento da folha de algodão com suspensão de caulim em água destilada a $60 \mathrm{~g} \mathrm{~L}^{-1}$, além da testemunha (água destilada) e quatro períodos de observação $(6,12,24$ e 48 horas).

Cento e sessenta lagartas de primeiro instar, recém-eclodidas, foram individualizadas em discos de folhas de algodão de 2,2 cm de diâmetro. Os discos foram imersos por $10 \mathrm{~s}$ em solução de um dos tratamentos - com ou sem caulim -, e colocados para secar ao ar por duas horas, antes de serem oferecidas às lagartas.
Os discos tratados e secos foram transferidos para caixas de plástico com tampa, que mediam $5,5 \mathrm{~cm}$ de comprimento, por 3,5 cm de largura e 3,0 cm de altura, e mantidas no seu interior até o término das observações. A turgidez dos discos foliares foi preservada com uso de um papel-filtro, com as mesmas dimensões do disco foliar, umedecido com água destilada e colocado sob o disco foliar. As caixas de plástico foram mantidas em câmara climatizada tipo BOD a $25 \pm 1^{\circ} \mathrm{C}, 68 \pm 10 \%$ de umidade relativa e 12 horas de fotófase até o término das observações.

As avaliações foram realizadas ao final de cada intervalo de tempo adotado, em que se coletaram 20 lagartas, alimentadas com discos foliares com ou sem caulim, com auxílio de um pincel, e montadas em lâminas para observação ao microscópio, com uso de uma solução de xarope de milho diluído em água. A quantidade de material vegetal encontrada no trato digestório das lagartas foi mensurado pelo cálculo de sua área, com uma lente ocular micrométrica, acoplada a um microscópio com contraste de fase e sob transmissão de luz, conforme Razze et al. (2011).

Os dados foram submetidos ao teste de normalidade de Liliefors e transformados, quando necessário, para atender aos pré-requisitos da análise de variância. Os dados obtidos nos testes de livre-escolha e confinamento foram submetidos à análise de variância, e as médias foram comparadas pelo teste de Tukey, a $5 \%$ de probabilidade. Os dados de consumo foliar das lagartas foram submetidos à análise de variância e de regressão. Os dados que apresentaram normalidade foram analisados pelo Sistema de Análises Estatísticas e Genéticas (Saeg) (Universidade Federal de Viçosa, Viçosa, MG, Brasil) e aqueles que não apresentaram normalidade, foram submetidos ao modelo linear generalizado com distribuição binomial (Crawley, 2002), com uso do Sistema Estatístico R (R Foundation for Statistical Computing, Viena, Áustria).

\section{Resultados e Discussão}

O número de posturas de $A$. argillacea em plantas de algodoeiro não apresentou interação significativa entre tratamentos e estruturas vegetais da planta com $\left(F_{6: 39}=2,07 ; p=0,08\right)$ ou sem chance de escolha $\left(\mathrm{F}_{6: 39}=1,67 ; \mathrm{p}=0,15\right)$, o que indica que as pulverizações com caulim não modificaram a quantidade relativa e a distribuição dos ovos da mariposa, nas diferentes 
estruturas vegetais. Isto se pode atribuir ao comportamento monófago de $A$. argillacea, que não dispõe de plantas alternativas para oviposição (Tate et al., 2006). Assim, na ausência de uma história coevolutiva como, por exemplo, folhas tratadas com caulim, as fêmeas podem escolher uma planta hospedeira com base em informações insuficientes e ignorar a presença de substâncias que possam afetar negativamente seu desenvolvimento (Kahuthia-Gathu et al., 2008). Isto foi observado em mariposas de $H$. armigera, em ensaios de campo com algodão (Alavo et al., 2010).

O número de ovos de $A$. argillacea, no dossel do algodoeiro, variou entre os tratamentos (Figura 1). No teste com chance de escolha, o número médio de posturas por planta com caulim e controle foi de 0,27 e 0,67 ovos, respectivamente; ou seja, mariposas dessa praga depositaram 2,5 vezes mais ovos em algodoeiros do tratamento-controle do que naqueles com caulim. Em condições de confinamento, o número médio de posturas de $A$. argillacea por planta com caulim e controle foi de 0,22 e 0,41 ovos, respectivamente; ou seja, mariposas dessa praga depositaram 1,8 vezes mais ovos em algodoeiros do tratamento-controle do que naqueles com caulim. O menor número de ovos de A. argillacea, depositados sobre algodoeiros tratados com caulim, tanto nos testes de escolha como em confinamento, é um indicativo de que as mariposas do curuquerê respondem de forma diferente e reconhecem tais modificações na coloração das plantas, pois preferem ovipositar em folhas de plantas sem caulim. O modo de ação do caulim parece ser efetivo contra artrópodes especialistas (monófagos), que dependem de estímulos específicos visuais, olfativos, gustativos e mecano-sensoriais, para selecionar uma planta hospedeira. Isto foi mostrado em estudo sobre Pectinophora gossypiella (Lepidoptera: Gelechiidae), em algodoeiros cultivados no condado de Yuma, USA, cujas mariposas apresentaram deterrência oviposicional, ovipositando até sete vezes menos em maçãs tratadas com caulim do que no controle (Sisterson et al., 2003). No entanto, isto pode não funcionar do mesmo modo contra insetos generalistas (polífagos), como observado em Spodoptera exígua (Lepidoptera: Noctuidae), cujo número de ovos depositados em algodoeiros tratados com caulim não diferiu do controle, embora tenham ovipositado $46 \%$ mais ovos e massa de ovos nessas plantas, em condições de confinamento (Showler, 2003).
A estrutura vegetal da planta de algodão com maior número de ovos de $A$. argillacea, nos testes de escolha e confinamento, foi a folha da haste de ambos os tratamentos (Tabela 1). No entanto, os menores números de ovos de $A$. argillacea, para ambos os tratamentos, foram observados na haste do algodoeiro, no teste de escolha, e nos botões florais e nas folhas do $5^{\circ}$ e $6^{\circ}$ ramos frutíferos, no confinamento.

A distribuição vertical dos ovos de A. argillacea variou entre as folhas da haste, tanto no teste com chance de escolha $\left(\mathrm{F}_{39: 6}=13,68 ; \mathrm{p}<0,01\right)$ como em confinamento $\left(F_{39: 6}=2,53 ; p<0,04\right)$. Esse maior número de ovos de $A$. argillacea, nas folhas da haste do algodão com ou sem caulim, tanto no teste de escolha como sob condições de confinamento, é um indicativo
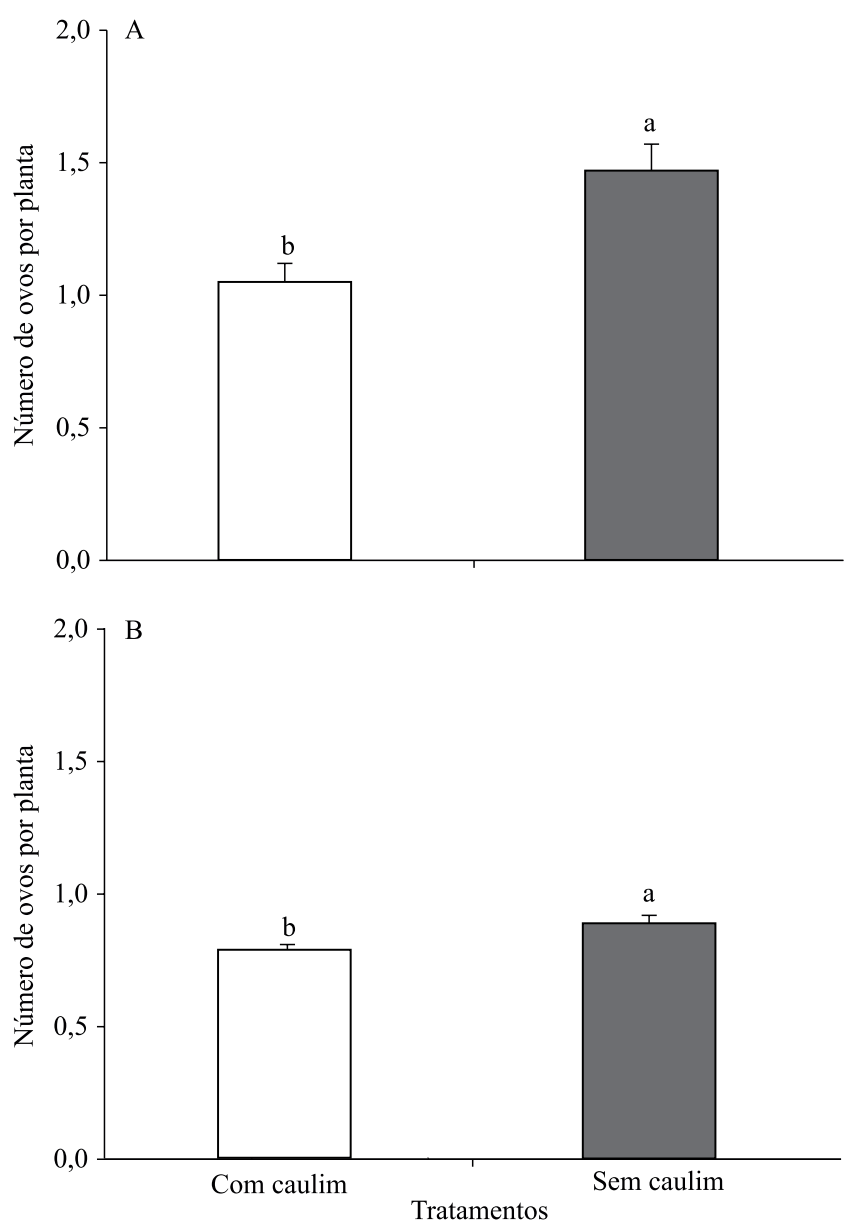

Figura 1. Número de ovos de Alabama argillacea (Lepidoptera: Noctuidae) por planta de algodão, em função dos tratamentos, nos testes de livre-escolha (A) e confinamento (B). Dados transformados em raiz quadrada de $(x+0,5)$. 
de que essa estrutura vegetal da planta é a preferida para postura dessa praga. Plantas de algodoeiro com aproximadamente 30 dias de idade apresentam poucas ramificações laterais, com a maioria das folhas da haste representada por folhas novas, que são as preferidas por lagartas neonatas do curuquerê para alimentação (Fernandes et al., 2007). Observou-se, também, preferência quanto à oviposição na primeira e terceira folhas da haste, com chance de escolha e em confinamento, respectivamente, que corresponde ao terço superior da cultivar de algodão BRS 286, o que corrobora resultados anteriores para a cultivar CNPA ITA 90 (Fernandes et al., 2007).

As percentagens de eclosão dos ovos de $A$. argillacea foram de $100 \%$ nos algodoeiros com ou sem caulim, tanto no teste de escolha como no confinamento, o que indica que o caulim, pulverizado sobre as folhas do algodoeiro, não afeta a viabilidade dos ovos (Tabela 1). Esses resultados corroboram os observados para posturas de Cydia pomonella (Lepidoptera: Tortricidae) em folhas de macieira, tratadas com caulim previa e posteriormente à oviposição das mariposas (Unruh et al., 2000). Segundo estes autores, embora houvesse uma tendência à redução da eclosão

Tabela 1. Viabilidade e número médio \pm erro-padrão de ovos de Alabama argillacea (Lepidoptera: Noctuidae) em teste com ou sem chance de escolha, em diferentes estruturas vegetais da planta com ou sem caulim(1).

\begin{tabular}{|c|c|c|c|}
\hline Estrutura vegetal & $\begin{array}{c}\text { Viabilidade } \\
(\%)\end{array}$ & $\begin{array}{l}\text { Número } \\
\text { total }\end{array}$ & $\begin{array}{l}\text { Número } \\
\text { médio }^{(2)}\end{array}$ \\
\hline & \multicolumn{3}{|c|}{ Teste com chance de escolha } \\
\hline Broto & 100 & 31 & $1,00 \pm 0,09 \mathrm{bc}$ \\
\hline Botão floral & 100 & 34 & $1,03 \pm 0,12 \mathrm{bc}$ \\
\hline Haste & - & 0 & $0,70 \pm 3,99 \mathrm{c}$ \\
\hline Folhas da haste & 100 & 216 & $2,35 \pm 0,23 a$ \\
\hline Folhas do $1^{\circ}$ e $2^{\circ}$ ramos frutíferos & 100 & 41 & $1,20 \pm 0,10 \mathrm{bc}$ \\
\hline Folhas do $3^{\circ}$ e $4^{\circ}$ ramos frutíferos & 100 & 74 & $1,45 \pm 0,14 b$ \\
\hline \multirow[t]{2}{*}{ Folhas do 5 o e $6^{\circ}$ ramos frutíferos } & 100 & 29 & $1,05 \pm 0,09 \mathrm{bc}$ \\
\hline & \multicolumn{3}{|c|}{ Teste sem chance de escolha } \\
\hline Broto & 100 & 45 & $0,87 \pm 0,07 \mathrm{ab}$ \\
\hline Botão floral & 100 & 10 & $0,75 \pm 0,04 \mathrm{~b}$ \\
\hline Haste & 100 & 53 & $0,85 \pm 0,10 \mathrm{ab}$ \\
\hline Folhas da haste & 100 & 103 & $1,01 \pm 0,13 \mathrm{a}$ \\
\hline Folhas do $1^{\circ}$ e $2^{2 o}$ ramos frutíferos & 100 & 35 & $0,84 \pm 0,06 \mathrm{ab}$ \\
\hline Folhas do $3^{\circ}$ e $4^{\circ}$ ramos frutíferos & 100 & 30 & $0,83 \pm 0,06 \mathrm{ab}$ \\
\hline Folhas do 5 o e $6^{\circ}$ ramos frutíferos & 100 & 6 & $0,74 \pm 0,02 \mathrm{~b}$ \\
\hline
\end{tabular}

${ }^{(1)}$ Dados transformados em raiz quadrada de $(x+0,5) .{ }^{(2)}$ Médias seguidas por letras iguais, minúsculas nas colunas, não diferem entre si, pelo teste de Tukey, a 5\% de probabilidade. de lagartas de C. pomonella, quando seus ovos foram depositados sobre resíduos de caulim, o efeito desse produto foi de pouca relevância biológica.

O consumo foliar de algodoeiro, por lagartas de primeiro instar de A. argillacea, não mostrou interação significativa entre tratamentos e períodos de observação $\left(\mathrm{F}_{152: 3}=0,32 ; \mathrm{p}>0,05\right)$, mas variou dentro dos tratamentos $\left(\mathrm{F}_{152: 1}=7,27 ; \mathrm{p}=0,01\right)$ e períodos $\left(\mathrm{F}_{152: 3}=2,59 ; \mathrm{p}=0,05\right)$. Lagartas alimentadas com folhas de algodoeiro com caulim consumiram 1,26 vez menos tecido vegetal e sobreviveram 1,20 vez menos do que aquelas alimentadas com folhas de algodoeiro sem caulim (Figura 2). O filme de partículas de
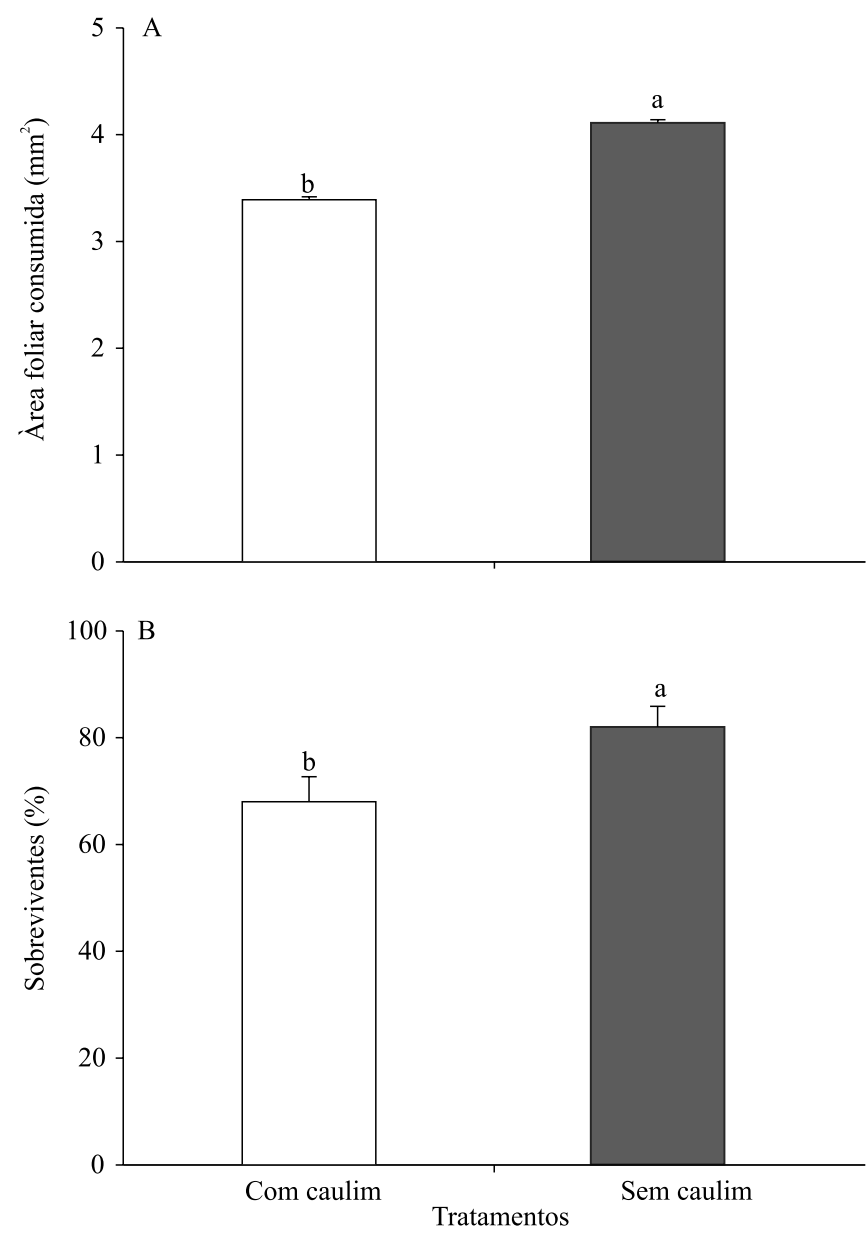

Figura 2. Área foliar de algodão consumida (A) por lagartas de primeiro instar de Alabama argillacea (Lepidoptera: Noctuidae) e sobreviventes (B) [Anodev, teste $\chi^{2}(\mathrm{p}=0,02)$ ], em função dos tratamentos. Dados transformados em raiz quadrada de $(\mathrm{x}+0,5)$. 
caulim pode alterar o gosto e a digestibilidade das plantas hospedeiras e, assim, reduzir a alimentação e a sobrevivência dos insetos imaturos (Showler, 2003; Sisterson et al., 2003; Cadogan \& Scharbach, 2005; Alavo, 2006; Alavo et al., 2010). No presente trabalho, o material vegetal de algodão, ingerido por lagartas de primeiro instar de $A$. argillacea, se mostrou mais fracionado e em menor quantidade dentro do trato digestório daquelas lagartas que se alimentaram de folhas tratadas com caulim.

As curvas de regressão polinomiais foram as que melhor explicaram o comportamento de consumo de lagartas de primeiro instar de A. argillacea, em algodoeiros com ou sem caulim, ao longo do tempo (Figura 3). Para ambos os tratamentos, observou-se aumento do consumo de folhas de algodão por lagartas, no período compreendido entre seis e 24 horas. Operíodo de maior consumo de folhas de algodão com ou sem caulim, pelas lagartas, ocorreu entre as 24 e 32 horas, do período de observação de 48 horas, desde quando as lagartas recém-eclodidas foram submetidas às folhas com ou sem caulim. A partir desse período, o consumo foliar decresceu acentuadamente, tendo chegado às 48 horas ao mesmo nível de consumo registrado às 12 horas. Tais resultados eram esperados, pois instares iniciais de lepidópteros, geralmente, apresentam taxas de crescimento relativo, consumo, metabólico e de

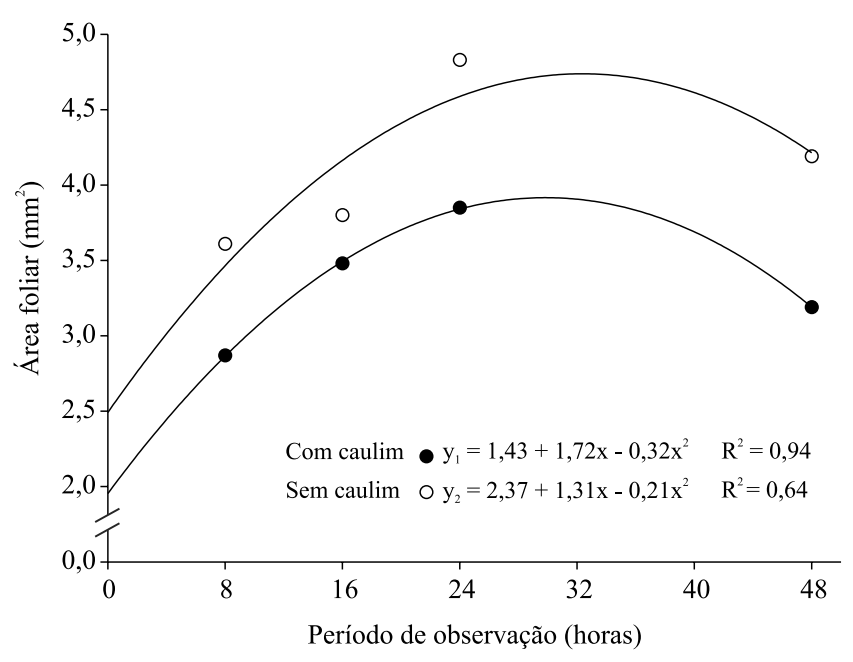

Figura 3. Área foliar de algodão 'BRS 286', com ou sem caulim, consumida por lagartas de primeiro instar de Alabama argillacea (Lepidoptera: Noctuidae), em função dos períodos de observação. eficiência de assimilação de alimento maior do que os instares finais (Scriber \& Slansky Jr., 1981). Esses estádios tendem a crescer mais rapidamente, consumir mais (em relação à massa corporal), e digerir melhor os alimentos, embora a conversão do alimento digerido seja menos eficiente (Zalucki et al., 2002), pois entre as mudas, a atividade metabólica conduz à intensificação da multiplicação celular e ao aumento do tamanho do inseto, concomitantemente à atividade alimentar e à acumulação de reserva para o processo de ecdise (Chapman et al., 2012). Na ecdise, em geral, os insetos não se alimentam, o que explica a redução do consumo em ambos os tratamentos, a partir das 32 horas.

Com os resultados do presente trabalho, mostrouse que o caulim reduz a oviposição das mariposas do curuquerê, dificulta sua alimentação e provoca mortalidade de lagartas de primeiro instar dessa praga. Assim, em condições de campo, a combinação destes efeitos do caulim sobre o curuquerê pode reduzir os níveis de danos desse lepidóptero-praga à cultura do algodão.

\section{Conclusões}

1. A oviposição das mariposas do curuquerê é reduzida nas plantas de algodão tratadas com caulim; porém, a viabilidade dos ovos não é afetada.

2. A folha da haste é a estrutura vegetal do algodoeiro preferida por mariposas do curuquerê para oviposição.

3. A sobrevivência e o consumo de lagartas de primeiro instar do curuquerê são menores nas plantas de algodão tratadas com caulim.

\section{Agradecimentos}

Ao Conselho Nacional de Desenvolvimento Científico e Tecnológico (CNPq) e à Coordenação de Aperfeiçoamento de Pessoal de Nível Superior (Capes), pelo apoio financeiro.

\section{Referências}

ALAVO, T.B.C. Biological control agents and eco-friendly compounds for the integrated management of cotton bollworm, Helicoverpa armigera Hübner (Lepidoptera: Noctuidae): perspectives for pyrethroid resistance management in West Africa. Archives of Phytopathology and Plant Protection, v.39, p.105-111, 2006. DOI: 10.1080/03235400500181576.

ALAVO, T.B.C.; ABAGLI, A.Z.; TÉGBÉSSOU, K.J.C.; DUNPHY, G.B. Kaolin potential for the integrated management of 
Aphis gossypii Glov. (Homoptera: Aphididae) on cotton. Archives of Phytopathology and Plant Protection, v.44, p.764-770, 2011. DOI: $10.1080 / 03235408.2010 .507959$.

ALAVO, T.B.C.; YAROU, B.B.; ATACHI, P. Field effects of kaolin particle film formulation against major cotton lepidopteran pests in North Benin, West Africa. International Journal of Pest Management, v.56, p.287-290, 2010. DOI: $10.1080 / 09670871003628389$.

ALVES, A.P.; SERIKAWA, R.H. Controle químico de pragas do algodoeiro. Revista Brasileira de Oleaginosas e Fibrosas, v.10, p.1197-1209, 2006

CADOGAN, B.L.; SCHARBACH, R.D. Effects of a kaolin-based particle film on oviposition and feeding of gypsy moth (Lep., Lymantriidae) and forest tent caterpillar (Lep., Lasiocampidae) in the laboratory. Journal of Applied Entomology, v.129, p.498-504, 2005. DOI: 10.1111/j.1439-0418.2005.01000.x.

CHAPMAN, R.F.; SIMPSON, S.J.; DOUGLAS, A.E. The insects: structure and function. Cambridge: Cambridge University, 2012. 929p. DOI: $10.1017 /$ CBO9781139035460.

COSTA, L.L.; FUNICHELlO, M.; BUSOLI, A.C. Parasitismo natural de ovos do curuquerê-do-algodoeiro por Trichogramma pretiosum (Hymenoptera: Trichogrammatidae) em diferentes estágios fenológicos de variedades de algodoeiro em Ipameri, GO. Bioscience Journal, v.26, p.281-286, 2010.

CRAWLEY, M.J. Statistical computing: an introduction to data analysis using S-plus. Chichester: J. Wiley, 2002. 772p.

EVANGELISTA JÚNIOR, W.S.; ZANUNCIO JÚNIOR, J.S.; ZANUNCIO, J.C. Controle biológico de artrópodes pragas do algodoeiro com predadores e parasitóides. Revista Brasileira de Oleaginosas e Fibrosas, v.10, p.1147-1165, 2006.

FERNANDES, M.G.; MOREIRA, M.A.S.; DEGRANDE, P.E.; CUBAS, A.C.; SILVA, A.M. Vertical distribution, population density, and natural egg parasitism of cotton leafworm on cotton under IPM. Revista Colombiana de Entomología, v.33, p.27-30, 2007.

GRIPENBERG, S.; MAYHEW, P.J.; PARNELL, M.; ROSLIN, T. A meta-analysis of preference-performance relationships in phytophagous insects. Ecology Letters, v.13, p.383-393, 2010. DOI: 10.1111/j.1461-0248.2009.01433.x.

KAHUTHIA-GATHU, R.; LÖHR, B.; POEHLING, H.M. Development and reproductive potential of diamondback moth Plutella xylostella (Lepidoptera: Plutellidae) on cultivated and wild crucifer species in Kenya. International Journal of Tropical Insect Science, v.28, p.19-29, 2008. DOI: 10.1017/ S1742758408901375.

MEDEIROS, R.S.; LEMOS, W.P.; RAMALHO, F.S. Efeitos da temperatura no desenvolvimento de Podisus nigrispinus (Dallas) (Heteroptera, Pentatomidae) predador do curuquerê-do-algodoeiro (Lepidoptera, Noctuidae). Revista Brasileira de Entomologia, v.42, p.121-130, 1998.

NEVES, R.C.S.; COLARES, F.; TORRES, J.B.; SANTOS, R.L.; BASTOS, C.S. Rational practices to manage boll weevils colonization and population growth on family farms in the Semiárido region of Brazil. Insects, v.5, p.818-831, 2014. DOI: $10.3390 /$ insects 5040818 .
PAPAJ, D.R.; RAUSHER, M.D. Individual variation in host location by phytophagous insects. In: AHMAD, S. (Ed.). Herbivorous insects: host-seeking behavior and mechanisms. New York: Academic Press, 1983. p.77-124. DOI: 10.1016/ B978-0-12-045580-5.50008-2.

PAVINATO, V.A.C.; BAJAY, M.M.; MARTINELLI, S.; MONTEIRO, M.; PINHEIRO, J.B.; ZUCHI, M.I.; OMOTO, C. Development and characterization of microsatellite markers for genetic studies of Alabama argillacea (Hübner) (Lepidoptera: Noctuidae): an important cotton pest in Brazil. Molecular Ecology Resources, v.11, p. 219-222, 2011.

QUIRINO, E. da S.; SOARES, J.J. Efeito do ataque de Alabama argillacea no crescimento vegetativo e sua relação com a fenologia do algodoeiro. Pesquisa Agropecuária Brasileira, v.36, p.1005-1010, 2001. DOI: 10.1590/S0100-204X2001000800001.

RAMALHO, F.S.; PACHÚ, J.K.S.; LIRA, A.C.S.; MALAQUIAS, J.B.; ZANUNCIO, J.C.; FERNANDES, F.S. Feeding and dispersal behavior of the cotton leafworm, Alabama argillacea (Hübner) (Lepidoptera: Noctuidae), on Bt and non-Bt cotton: implications for evolution and resistance management. Plos One, v.9, article e111588, 2014. DOI: 10.1371/journal.pone.0111588.

RAZZE, J.M.; MASON, C.E.; PIZZOLATO, T.D. Feeding behavior of neonate Ostrinia nubilalis (Lepidoptera: Crambidae) on Cry1 Ab Bt corn: implications for resistance management. Journal of Economic Entomology, v.104, p.806-813, 2011. DOI: 10.1603/EC10287.

SACKETT, T.E.; BUDDLE, C.M.; VINCENT, C. Effect of kaolin on fitness and behavior of Choristoneura rosaceana (Lepidoptera: Tortricidae) Larvae. Journal of Economic Entomology, v.98, p.1648-1653, 2005. DOI: 10.1093/jee/98.5.1648.

SACKETT, T.E.; BUDDLE, C.M.; VINCENT, C. ffects of kaolin on the composition of generalist predator assemblages and parasitism of Choristoneura rosaceana (Lep., Tortricidae) in apple orchards. Journal of Applied Entomology, v.131, p.478-485, 2007. DOI: 10.1111/j.1439-0418.2007.01199.x.

SCRIBER, J.M.; SLANSKY JR., F. The nutritional ecology of immature insects. Annual Review of Entomology, v.26, p.183-211, 1981. DOI: 10.1146/annurev.en.26.010181.001151.

SHOWLER, A.T. Effects of kaolin particle film on beet armyworm, Spodoptera exigua (Hübner) (Lepidoptera: Noctuidae), oviposition, larval feeding and development on cotton, Gossypium hirsutum L. Agriculture, Ecosystems and Environment, v.95, p.265-271, 2003. DOI: 10.1016/S0167-8809(02)00101-9.

SILVA, C.A.D.; RAMALHO, F.S. Kaolin spraying protects cotton plants against damages by boll weevil Anthonomus grandis Boheman (Coleoptera: Curculionidae). Journal of Pest Science, v.86, p.563-569, 2013. DOI: 10.1007/s10340-013-0483-0.

SILVA, F.C. da. (Ed.). Manual de análises químicas de solos, plantas e fertilizantes. 2.ed. Brasília: Embrapa Informação Tecnológica; Rio de Janeiro: Embrapa Solos, 2009. 627p.

SILVA, T.B.M.; SIQUEIRA, H.A.A.; OLIVEIRA, A.C.; TORRES, J.B.; OLIVEIRA, J.V.; MONTARROYOS, P.A.V.; FARIAS, M.J.D.C. Insecticide resistance in Brazilian populations of the cotton leaf worm, Alabama argillacea. Crop Protection, v.30, p.1156-1161, 2011. DOI: 10.1016/j.cropro.2011.05.022. 
SISTERSON, M.S.; LIU, Y.B.; KERNS, D.L.; TABASHNIK, B.E. Effects of kaolin particle film on oviposition, larval mining, and infestation of cotton by pink bollworm (Lepidoptera: Gelechiidae). Journal of Economic Entomology, v.96, p.805-810, 2003. DOI: 10.1093/jee/96.3.805.

TATE, C.D.; HELLMICH, R.L.; LEWIS, L.C. Evaluation of Ostrinia nubilalis (Lepidoptera: Crambidae) neonate preferences for corn and weeds in corn. Journal of Economic Entomology, v.99, p.1987-1993, 2006. DOI: 10.1093/jee/99.6.1987.
UNRUH, T.R.; KNIGHT, A.L.; UPTON, J.; GLENN, D.M.; PUTERKA, G.J. Particle films for suppression of the codling moth (Lepidoptera: Tortricidae) in apple and pear orchards. Journal of Economic Entomology, v. 93, p.737-743, 2000. DOI: 10.1603/0022-0493-93.3.737.

ZALUCKI, M.P.; CLARKE, A.R.; MALCOLM, S.B. Ecology and behavior of first instar larval Lepidoptera. Annual Review of Entomology, v.47, p.361-393, 2002. DOI: 10.1146/annurev. ento.47.091201.145220.

Recebido em 27 de novembro de 2014 e aprovado em $1^{\circ}$ de junho de 2015 